\title{
WHO reports decline in number of new Ebola cases in Liberia
}

\author{
Anne Gulland
}

London

The number of newly reported cases of Ebola virus disease in Liberia is falling, with reports of empty beds in treatment centres, the World Health Organization has said.

At a press conference Bruce Aylward, WHO assistant director general in charge of the operational response to Ebola, reported a "glimmer of hope"- the number of newly reported cases is beginning to decline, treatment centres are reporting empty beds, and the number of burials is also falling. In the capital, Monrovia, and the district of Lofa in particular the number of new cases appears to have plateaued, he said.

He said that there had been about a $25 \%$ drop in the number of new cases reported over recent weeks but stressed that accurate figures were not yet available. The Liberian government is looking into the data to understand whether this is a real decline in numbers or whether it is due to under-reporting or underdetection of cases. "But on the information we have received to date it appears that the trend is real in Liberia, and there's a slowing of the epidemic there," said Aylward.

He added that the Liberian government and WHO were trying to "untangle" the reasons for the drop in the number of new cases but that strong community engagement and behaviour change coupled with a rise in the number of safe burials taking place were the most likely causes.

He said that there were grounds for "cautious optimism" but warned that there could be an "oscillating pattern," with the number of cases going up and down, as witnessed in Gueckedou in Guinea, one of the first places to report cases of Ebola. He added that Guinea and Sierra Leone were still seeing an upward trend in the number of new cases. "Ebola is not under control. That's like saying your pet tiger is under control," he said.

The latest data from WHO on 29 October showed that there have been a total of 13703 cases of the disease since the outbreak began, including more than 4922 deaths. There have been 6535 cases in Liberia, 5235 in Sierra Leone, and 1906 in
Guinea, as well as cases in Senegal, Nigeria, Mali, the United States, and Spain.

WHO's previous report on the disease, dated 25 October, showed 4665 cases of Ebola in Liberia. Aylward said that the discrepancy between this figure and reports of a slowing in the rise of new cases was due to the fact that there had been a backlog in the reporting of the data and that most of these "new" cases were probably about two weeks old.

He said that 56 Ebola treatment centres, with 4700 beds, would be built by the end of November. Some 15 centres with 1740 beds are already up and running, and 22 will be functional by the end of November. The remaining 19 would be built by next month but there were not enough healthcare staff to get them operational. Despite the downward trend in Liberia Aylward said that the treatment centres and beds were still needed. "It would be a huge mistake for anybody to think we are getting on top of this virus and we can scale back," he said.

The UK Disasters Emergency Committee has launched an appeal for Ebola - the first time the committee has made an appeal for a disease outbreak. This comes after United Nations secretary general Ban Ki Moon appealed for 5000 more foreign medical staff. The money will go towards the full emergency response including contact tracing, safe burials, and staff for treatment centres.

Meanwhile Australia has shut its borders to citizens of Sierra Leone, Guinea, and Liberia, cancelling new non-permanent or temporary visas. Sierra Leone's information minister Alpha

Kanu described the move as "too draconian" and "discriminatory."

Access all of The BMS s content on the ongoing Ebola outbreak at thebmj.com/ebola.

Cite this as: $B M J$ 2014;349:g6542

๑) BMJ Publishing Group Ltd 2014 